\title{
A Universidade e o futuro: percepção de docentes universitários
}

\author{
Luís Sebastião ${ }^{1}$
}

Elisa Chaleta²

\section{RESUMO}

Nesteartigo procura-seconhecera percepção dosprofessores sobreauniversidadena actualidade. A percepção de Universidade surge, na voz dos professores, centrada na descrição da sua missão, em particular como contexto de produção e difusão de conhecimento para a sociedade, como espaço de pensamento criativo e crítico sobre o mundo, como espaço interdisciplinar e como sistema centrado no ensino e na investigação. Inclui, também, características relativas à sua estrutura e funcionamento como a excessiva hierarquização, burocratização, competitividade, desumanização e hipervalorização da bibliometria.

\section{PALAVRAS-CHAVE}

Universidade; Ensino Superior; Percepção de Professores Universitários; Análise Fenomenológica Interpretativa. 


\section{ABSTRACT}

In this article we try to know the perception of the teachers about the university now. The perception of the university arises, in the voice of teachers, centered in the description of its mission, as a context of production and diffusion of knowledge for society, as a place for creative and critical thinking about the world, as an interdisciplinary field and as a system centered in teaching and research. It also includes characteristics related to its structure and functioning such as excessive hierarchization, bureaucratization, competitiveness, dehumanization and excessive bibliometric criteria.

\section{KEYWORDS}

University; Higher Education; Perception of University Teachers; Interpretative Phenomenological Analysis.

\section{RESUMEN}

En este artículo se pretende conocer la percepción de los profesores sobre la Universidad actual. La percepción de la Universidad surge, en la voz de los docentes, centrada en la descripción de sumisión, en particular como contexto de producción y difusión del conocimiento para la sociedad, como espacio de pensamiento creativo y crítico sobre el mundo, como espacio interdisciplinar y como sistema centrado en la enseñanza y en la investigación. Incluye también características centradas en su estructura y funcionamiento como una excesiva jerarquización, burocratización, competitividad, deshumanización y criterios bibliométricos excesivos.

\section{PALABRAS CLAVE}

Universidad; Educación Superior; Percepción del Profesorado Universitario, Análisis Fenomenológico Interpretativo. 


\section{INTRODUC̦ÃO}

Se há palavras que contêm um verdadeiro sortilégio, uma delas é Universidade. Ela evoca, transversalmente no espaço e no tempo, respeitabilidade, confiança, prestígio. Durante séculos, quem frequentava esta instituição secular tinha assegurado um estatuto social elevado, acesso garantido a profissões liberais bem remuneradas a uma proeminência inquestionada. Esta quase sacralidade a que a Universidade se guindou manteve-a, por muito tempo, ao abrigo de um verdadeiro escrutínio da sua natureza, do seu funcionamento, da sua missão e dos seus efectivos frutos. Uma das consequências desse facto foi a de que se pensava nela como numa realidade única. Como se ao nomeá-la, em diferentes momentos da história ou em múltiplos lugares do mundo, nos estivéssemos a referir a uma mesma realidade.

Na verdade não é assim. A Universidade assumiu, ao longo da história, múltiplas formas, variadas funções, atribuiu-se diferentes missões. Em qualquer dos casos, foi na Modernidade, e enquanto ela durou, que esta instituição de ensino superior viveu o seu máximo fulgor. E, com o fim da modernidade chegou o fim da Universidade tal como a conhecíamos. É a este título muito ilustrativo que A Condição Pós-moderna de Jean-François Lyotard, on de denuncia o fim das grandes narrativas en quanto maneira de legitimar o conhecimento e fundar a Verdade [Lyotard, 1984] e que começou por ser um relatório sobre a condição do saber nas sociedades mais desenvolvidas encomendado pelo Conselho das Universidades junto do governo do Quebeque. Esta encomenda mostra como o mundo das universidades tem sentido a urgência de se pensar. Desde aí que este debate se tem vindo a intensificar e a alargar, ao ponto de já não ser possível abarcar num único olhar a imensa bibliografia produzida a este respeito.

A Universidade, tal como a conhecemos hoje, é a instituição moderna por excelência e é em nome da modernidade que tem sido discutida e modificada, entendida aqui como a governação da vida, pessoal e colectiva, segundo os ditames da razão. Basta para fundamentar esta afirmação verificar que autores como Michel Foucault [1969/2009] e Habermas (1990) consideraram "A luta das Faculdades", precedido de "O que é o lluminismo?", de Immanuel Kant, como os textos fundadores simultaneamente do pensamento acerca da modernidade e acerca da instituição universitária. Para Kant [1995], as Faculdades são a autoridade suprema onde a capacidade de julgar deve ser livremente exercida. Sendo a Universidade, nesta concepção, um conjunto de Faculdades, a sua missão consiste em desenvolver os diversos ramos do saber, devendo ser completamente independentes do controlo do governo do Estado. Ao Estado competiria, apenas, regular a forma como os formados por essas faculdades exerceriam as funções para que estas os prepararam [Faria, 2003].

Sublinhe-se esta pedra de toque que marca profundamente, ainda hoje, a identidade da universidade enquanto instituição: a autonomia do trabalho aí realizado face aos poderes políticos. Esta posição iniciada por Kant vem a ser levada ao seu extremo por Humboldt[1810/1997], na Universidade de Berlim, e no sistema educativo universitário alemão em geral, onde os professores investigam o que querem, ensinam o que investigam e os estudantes investigam e aprendem o que querem. São os alunos que traçam os seus percursos de aprendizagem e se submetem a exames finais quando querem. Uma outra característica interessante da universidade humboldtiana, e do sistema alemão, é que os alunos podem mudar de universidade quando querem e os professores têm que mudar, forçosamente, de universidade se querem progredir na carreira. Esta é, hoje, outra pedra de toque do pensamento dominante acerca da Universidade: que a mobilidade dos professores e dos estudantes é um bem a ser procurado [Faria, 2003]. 
A Universidade alemã valoriza ao limite o conhecimento enquanto tal e é o indivíduo quem deve ser cultivado e não o cidadão. O sistema é completamente avesso a um qualquer modelo de educação nacional. É da tensão entre o indivíduo e o Estado que resulta a evolução e o progresso. A marca da dialética hegeliana é, aqui, indesmentível.

É ainda no século XVIII que um influentíssimo pensador escocês,Adam Smith,"abre a porta" a uma concepção da universidade comprometida com a utilidade do saber para o progresso da sociedade. Para uma universidade comprometida, portanto. Afirma a importância de uma organização da instituição e dos saberes centrados nas necessidades sociais. Teoriza uma escola a que a classe média possa aceder e em que os professores sejam pagos em função do desempenho. A evolução desta tendência, sob influência de Bentham, leva ao surgimento, no século XIX, da Universidade de Londres como instituição laica, preocupada com o desenvolvimento de competências profissionais e com a sua abertura a classes sociais menos favorecidas [Faria, 2003).

É possivel encontrar aqui, em Adam Smith e, um pouco mais tarde, em Jeremy Bentham, o início do percurso que levará à supremacia da razão instrumental sobre a razão crítica e emancipatória tão característica das sociedades pós-modernas.

Já as chamadas Grandes Écoles fundadas a partir do século XVIII em França correspondem ao desígnio de, sob a administração central do Estado, fazer a formação de alto nível de funcionários para o Estado e a sua administração. Sendo um sistema fortemente elitista, tem uma preocupação essencialmente técnico-profissional. Ainda hoje as Grandes Écoles mantêm um enorme prestígio. Como nota de curiosidade, assinale-se que os Engenheiros licenciados pela Escola Politécnica de Paris, por exemplo, têm maior empregabilidade e melhor estatuto remuneratório que os oriundos das universidades francesas [Faria, 2003].

Naturalmente que sobre estas três orientações identificadas paira o modelo arquetípico das Universidades de Oxford e de Cambridge, como aquelas que consubstanciam o ideal de formação das elites culturais e políticas. 0 locus por excelência da educação liberal visando a formação de um cidadão cosmopolita (Newman, 1854).

Todos estes modos de conceber e organizar as universidades persistem hoje. E persistem como tensões internas a cada instituição. Na verdade, mais do que o fenómeno de bilinguismo identificado por Fulton nas universidades britânicas [Jesuíno, 2016], parece estarmos face a uma poliglotia que arrisca tornar-se numa verdadeira cacofonia. Os docentes assumem - são forçados a assumir - o discurso do investigador, do servidor público, do agente económico e do guardião dos grandes valores civilizacionais.

É conhecimento comum que a História acelerou vertiginosamente a partir do pós-guerra e, com isso, entrámos num período de difícil catalogação: pós-ideológico, pós-histórico, pós-moderno, modernidade líquida, etc., caracterizado, fundamental e inexoravelmente, pela deslegitimação e pela des-referencialização dos saberes. Naturalmente que a Universidade, enquanto lugar de produção, legitimação e divulgação do mais alto saber entrou, forçosamente, em convulsão. Tornou-se, portanto, simultaneamente imperioso, mas quase impossivel, redefinir o estatuto e a missão da universidade nesta contemporaneidade.

Provavelmente, aquilo a que estamos a assistir pode ser caracterizado, como refere Bill Readings como a americanização da universidade. Americanização entendida como expansão da hegemonia 
cultural dos Estados Unidos da América mas, sobretudo, como "a imposição generalizada do regime da lógica do dinheiro em substituição da noção de identidade natural como instância que determina todas as formas de investimento na vida social. Isto é, a 'americanização' implica o fim da cultura nacional" [Readings, 2003, p. 12).

Perdida esta função de produção de uma cultura nacional, de legitimação de uma organização política e social, a Universidade tem vindo a transformar-se em empresa e a reger-se por princípios de prestação de contas, eficácia e eficiência, funcionarização e desprofissionalização dos docentes [Roldão, 2005; Paquay, Altet, Charlier \& Perrenoud, 1998). É ainda Readings [2003] quem assinala o facto de,a par com a empresarialização das Universidades, se ter assistido à emergência do conceito de excelência, que se tornou central, mas é autorreferenciado e absolutamente vazio de conteúdo. E afirma: "a história dos modos anteriores de compreender a função da universidade pode ser assim resumida: a universidade moderna já teve três ideias o conceito kantiano de razão, a ideia humboldtiana de cultura e agora a noção tecno-burocrática de excelência" (Readings, 2003, p. 24).

No mesmo sentido pensa Jesuíno [2016], que afirma que a actual viragem neoliberal, em que os "mercados" assumem a centralidade, está a conduzir as universidades a configurarem-se como empresas [ainda que mais flexíveis nos seus estilos de gestão] muito direcionadas para culto da eficiência [fazer mais com menos] e a considerar o conhecimento não como um fim mas como um meio, um instrumento [suscetivel de mais valia económica para a instituição, dizemos nós].

A cultura empresarial, que por um lado se pode traduzir em maior liberdade de actuação e autonomia, implica, por outro lado, maior controlo e verticalização. Nas universidades, a mudança de organização que implica passar de modelos horizontais para modelos verticais acaba por encontrar resistência e, segundo Leite [2003], causar perplexidade nos docentes, e mesmo dirigentes, ao ter impacto no redireccionamento da investigação (da básica para a aplicada], no agrupamento e concentração/fusão dos tradicionais departamentos e institutos que se realiza em nome de um certo conceito de eficiência reforçado pela imposição de mecanismos de avaliação interna e externa. Nos estudos realizados por Fulton [2003] em várias universidades britânicas os resultados mostraram ambivalência colectiva acerca da desejabilidade das mudanças, oscilando entre a identificação com os objectivos gestionários considerados razoáveis e a identificação com os valores académicos tradicionais e mais cépticos [Chaleta, Pissarra \& Jesuino, 2018]. Barnett [2004] refere a variedade de textos produzidos mais recentemente em que ressaltam essencialmente duas linhas de pensamento: i] uma mais conservadora marcada por um ideal de educação superior mais separada da sociedade que tenta identificar espaços intelectuais que justifiquem a universidade como um fim em si, outra, ii] mais marcada pela persuasão pós-moderna assente na ideia de que a universidade tem apenas fins instrumentais ou que se contenta mais com a sua forma do que com a sua própria substância. Ambas as posições são limitadas para a situação contemporânea das universidades, tornando-se necessário um olhar mais abrangente sobre a complexidade de uma universidade inexoravelmente entrelaçada com a sociedade em geral e que não se pode alhear dos novos espaços e dos novos desafios universais.

Alguns aspectos devem ser tidos em conta quando falamos de ensino superior. Por norma, o termo coincide com instituições de ensino superior pelo que alguma literatura vem insistindo no conceito de "educação superior". Quando nos referimos a instituições de ensino superior é preciso ter em conta a sua diversidade tanto em termos de dimensão, financiamento, liderança em investigação e muitos outros aspectos pelo que se torna redutor produzir uma discussão 
em torno da ideia de "universidade". Na mesma linha há que diferenciar ensino superior e universidade pois nem todas as instituições de ensino superior são universidades, embora o uso do termo universidade seja o "rótulo valorizado para uma empresa" [Barnett, 2004, p.62) e, em muitos países, o termo universidade seja um título protegido e conferido pelo Estado em certas condições.

Um marco que não pode deixar de ser referido no contexto das mudanças do ensino superior, até mesmo pelo papel de acelerador dessas mudanças nas últimas duas décadas é a Declaração de Bolonha assinada em 1999 por representantes de 29 países europeus [actualmente 47]. 0 documento propõe, à época, a criação do Espaço Europeu do Ensino Superior competitivo a nível internacional, capaz de promover a mobilidade e a empregabilidade dos seus cidadãos e visa uma maior compatibilidade e comparabilidade dos sistemas de ensino superior. Apesar dos seus objetivos iniciais ambíguos e vagos (Neave, 2002), a perspectiva de longo prazo do processo [Witte, Huisman, \& Purser, 2009], a mudança da agenda política ao longo do tempo [Kehm, Huisman, \& Stensaker, 2009] e a mudança dos actores envolvidos no processo [Keeling, 2006; Neave \& Maassen, 2007] muito foi alcançado na primeira década do processo influenciando mudanças mais globais e que ultrapassaram claramente o espaço europeu.

Ao crescente sucesso dos programas de mobilidade, da transparência [e reconhecimento] de programas e diplomas estrangeiros e definição de como os créditos obtidos no exterior contariam para o grau de origem associaram-se, progressivamente, imperativos económicos mais amplos. A ideia europeia de livre circulação de capital, bens, serviços e pessoas foi gradualmente transferida para o domínio do ensino superior [De Wit \& Verhoeven, 2001] e os esforços tradicionais de cooperação adoptaram outro plano: o da harmonização e integração. Esta vertente foi acentuada na denominada Estratégia de Lisboa (Conselho Europeu, 2000), bastante semelhante ao processo de Bolonha [Van der Wende \& Huisman, 2004) que tinha como meta ambiciosa dotar a União Europeia de uma economia baseada no conhecimento, no sentido de se tornar a mais competitiva e dinâmica do mundo até 2010.Tal tornou-se possível com o envolvimento da Comissão Europeia em termos de financiamento da investigação, da profissionalização e da aprendizagem ao longo da vida. Embora o principal foco deste processo fosse essencialmente a investigação, o desenvolvimento e a inovação[Witte, 2006) acaba por também ter impacto na malha do ensino e da aprendizagem pois a maioria das instituições de ensino superior europeias comportam ambas as componentes [ensino e investigação].As várias medidas adoptadas levaram, cada vez mais, ao entrelaçamento gradual dos processos supranacionais e intergovernamentais [Keeling, 2006; Gornitzka, 2010),o que determinou, de forma muito rápida, a evolução do processo de Bolonha de um processo político intergovernamental para um processo de governança multinível e multi-actor [Witte, 2006).

Apesar das linhas de acção terem mudado ao longo do tempo são hoje centrais a estrutura de três ciclos, os quadros nacionais de qualificações, a garantia da qualidade, o reconhecimento de qualificações, créditos e aprendizagem prévia, a mobilidade de estudantes e funcionários e a dimensão social do Espaço Europeu de Ensino Superior [Rauhvargers, 2011; Westerheijden, et al., 2010]. Pode-se considerar, assim, que os principais elementos arquitetónicos da Declaração foram implementados na maioria dos países europeus, traduzidos em legislação e regulamentação nacional, apesar das diferentes trajetórias políticas seguidas pelos países para alcançarem os objetivos que dependem das idiossincrasias nacionais, dos diferentes pontos de partida, das diferentes velocidades de implementação,das diferentes agendas políticas nacionais e das diferentes percepções dos agentes de mudança [instituições, gestores, profissionais]. 
A consolidação do processo de Bolonha na Europa ganhou também uma dimensão externa [Zgaga, 2006]. Num contexto globalizado grandes desenvolvimentos numa região, com suporte considerável de um número significativo de governos nacionais, despertariam, inevitavelmente, a atençãode outras regiões. Empreendimentos de larga escala numa parte do mundo têmnaturalmente consequências reais para outras regiões. Uma delas foi tornar o espaço europeu de ensino superior o concorrente padrão dos EUA em consequênciada nova estrutura de graduação, reforçada pela introdução de sistemas de garantia de qualidade,com impacto positivo na percepção do reconhecimento da qualidade do ensino superior europeu com efeitos [também competitivos] na captação de estudantes internacionais. Alguns estudos dão conta de desenvolvimentos do tipo Bolonha na região Ásia-Pacífico, América Latina, Estados Unidos e África o que acabou por determinar maior transparência das qualificações nos EUA, preocupações com a garantia de qualidade na Ásia e a mobilidade em África[Huisman, Adelman, Hsieh, Shams, \& Wilkins, 2012].

Facto inegável é que o ensino superior está a mudar com notável rapidez. À mudança da educação de elites para a educação de massas associam-se hoje fenómenos como a globalização, a mercantilização do ensino superior [serviços de conhecimento para potenciais clientes], a estreita ligação à sociedade, agendas de inclusão [participação, acesso e igualdade de oportunidades], a revolução das tecnologias digitais, o potencial de internacionalização,os rankings e os mecanismos de avaliação da qualidade patrocinadas pelo Estado que acentuam a concorrência entre as instituições.

Na sociedade do conhecimento [ou economia do conhecimento] globalizada duas tendências particulares merecem destaque: a internacionalização e a as abordagens multidisciplinares. A sociedade do conhecimento requer líderes capacitados [e mão-de-obra] capazes de enfrentar os muitos e novos desafios que se colocam a empresas, governos e sociedades do mundo em geral e que exigem abordagens e soluções inovadoras. As instituições de ensino superior não são mais capazes de formar graduados para abordar todos os desafios atuais e emergentes a partir de uma fonte disciplinar única, pelo que a pressão está cada vez mais na necessidade de abordagens interdisciplinares tanto ao nível da investigação como da preparação para futuros empregos [ainda pouco precisos] e posições de liderança. Esta necessidade requer também esforços integrados de investigadores de várias áreas de especialização e de várias origens, o que introduz novos níveis de complexidade tanto ao nível da investigação como da formação.

É nesta perspectiva que Barnett [2000] introduz o conceito de "mundo supercomplexo", um mundo onde nada pode ser entendido com certeza ou segurança ou dado como garantido. Nele somos continuamente desafiados conceptualmente pois são as próprias estruturas pelas quais nos orientamos para o mundo que são contestadas. A supercomplexidade envolve uma fragilidade resultante da mudança social e tecnológica e, ainda mais relevante, uma fragilidade "na maneira como entendemos o mundo, na maneira como nos entendemos e nos modos como nos sentimos seguros a agir no mundo" [Barnett, 2000, p.257). É expectável que neste quadro tão liquido e difuso a mudança se torne ainda mais difícil.

Que a Universidade se encontra num momento crítico, à procura da sua identidade, à procura dos caminhos que the permitam corresponder aos anseios da comunidade, aos interesses dos seus financiadores e aos desígnios dos seus actores, ninguém parece duvidar. João Vasconcelos e Costa num livro que fez furor nos meios académicos no fim do século passado disse-o desassombradamente. Mas disse também que a Universidade é uma instituição muito 
resistente à mudança [Costa, 1998). Só envolvendo todos os actores institucionais no processo de mudança - e começando por discutir o que é e para que serve a Universidade - teremos condições para levar efeito essas mudanças necessárias.

Assim, o estudo que apresentamos pretende contribuir para essa discussão começando por conhecer o que pensam alguns dos seus actores, neste caso os professores universitários. É objectivo central deste trabalho conhecer o que pensam os professores universitários sobre a Universidade na actualidade.

\section{MÉTODO}

O presente estudo é enquadrado pelo paradigma qualitativo tendo subjacente a preocupação com a definição e aprofundamento não só da forma como se produz conhecimento, mas também dos processos implicados na construção desse mesmo conhecimento [Rey, 1999]. Assim, assumese neste estudo a inclusão da subjectividade tanto do investigador como do sujeito investigado no próprio acto de investigar e uma visão de abrangência relativamente ao fenómeno estudado, considerando e realçando a sua inscrição em outros fenómenos mais vastos contextualizandoos a partir daí, como propõe Holanda [2006], o que permite uma abordagem empírica de fenómenos humanos invisíveis como crenças, representações, percepções, estilos pessoais de relacionamento com o outro, estratégias face a problemas e tomada de decisão. Como afirmam Gallagher e Zahavi [2008), a percepção do sujeito sobre uma determinada realidade não é apenas recepção de informação implica, também, interpretação que frequentemente se modifica em função do contexto.

$\mathrm{Na}$ investigação qualitativa a análise da experiência vivida ocupa um lugar central (Moustakas, 1994]. Nesta abordagem qualitativa e fenomenológica importa a busca do significado oculto das coisas sendo certo que aquilo que essas coisas [fenómenos, manifestações, ocorrências, ideias, vivências, sentimentos] significam para o indivíduo moldam e assumem um papel organizador na sua vida [Holanda, 2006].

Neste estudo optámos por recorrer à Análise Fenomenológica Interpretativa [Interpretative Phenomenological Analysis / IPA] proposta por Smith [1996], capaz de captar os aspectos experienciais e qualitativos da vida humana. A IPA tem como primeiro alicerce os métodos fenomenológico, hermenêutico e ideográfico. O método fenomenológico reconhece a impossibilidade de se ter acesso directo aos mundos vivenciais dos sujeitos sendo, inevitavelmente, uma interpretação da experiência do participante [perspectiva próxima de Heidegger e Gadamer]. Tal compromisso assume uma expressão prática através de uma série de etapas que permitem ao investigador identificar temas integrando-os em agrupamentos significativos primeiro numa perspectiva intra-caso e a seguir numa perspectiva inter-caso [Falcão, 2013]. A hermenêutica, em particular a partir de Heidegger, é segundo alicerce da IPA. De uma maneira geral, os teóricos da hermenêutica visam determinar os métodos e objectivos da interpretação, a viabilidade de decifrar as intenções ou significados originais de um dado autor e descobrir a relação entre o contexto produtor de um texto [a sua génese] e o contexto da sua interpretação bem como a sua relevância para a actualidade [Smith, Flowers \& Larkin, 2009]. 0 terceiro alicerce da IPA, a ideografia, está ligada ao estudo do particular e pretende a focalização na subjectividade inerente aos indivíduos contrariamente à perspectiva nomotética que visa a medição, a agregação e as inferências estatísticas [Falcão, 2013]. 
No estudo que realizámos o compromisso com a IPA envolve dois níveis: i] empenho no estudo do detalhe, e, neste sentido, um interesse claro pela profundidade da análise que desta forma deve ser completa, meticulosa e sistemática e ii] empenho na compreensão de como os fenómenos experienciais particulares foram interiorizados pelos indivíduos.

\section{PARTICIPANTES}

A seleção dos participantes foi realizada mediante contacto prévio com os professores que no momento lecionavam a cursos de formação de professores de vários níveis de ensino e se disponibilizaram para participar no estudo. A opção por estes professores deveu-se a um particular interesse em conhecer a perspetiva de docentes com maior afinidade com a área da educação.

Dos quinze professores que inicialmente se disponibilizaram para participar no estudo apenas dez responderam [67\%].

Os participantes neste estudo apresentam idades entre os 47 e os 65 anos de idade [média de 52 anos], sendo nove do sexo feminino e um do sexo masculino. Quatro docentes têm entre 15 e 20 anos de tempo de serviço na universidade, cinco entre 20 e 30 anos e um 40 anos. Em relação à formação inicial dois docentes [S5 e S7] referem formação na área das Ciências da Educação, quatro na área das Ciências Exactas sendo que destes três realizaram formação específica para a docência [S1, S2 e S9] e um na área das humanidades sem formação para a docência [S4]. Dois dos docentes não responderam a este aspecto [S6 e S10].

Podemos também observar que quase todos os docentes têm o grau de doutor há mais de dez anos havendo apenas um que obteve o grau mais recentemente [S 5]. Em relação aos cursos a que lecionam podemos observar que seis referem o 1ำ e $2^{\circ}$ Ciclo de Educação Pré-Escolar e Ensino Básico e quatro referem participar na lecionação dos Mestrados em Ensino [Ensino Básico e Secundário].

\section{INSTRUMENTOS E PROCEDIMENTOS}

0 trabalho que apresentamos inscreve-se num trabalho mais amplo sobre a perspectiva dos professores universitários sobre a Universidade na actualidade. Num primeiro momento definimos, a partir da literatura, um conjunto de questões que apresentámos posteriormente, num estudo exploratório, a dois docentes com o objectivo de averiguar a pertinência, clareza e compreensibilidade das questões. Apresentamos em seguida os resultados relativos à questão "Para si o que é a Universidade?" uma das questões que integrava um questionário aberto que enviámos aos docentes por via electrónica. 0 critério de registo consistiu na anotação de todas as diferentes afirmações presentes no discurso de cada participante como pertencentes a determinado tema ou categoria e não no número de vezes que foram referidas por cada um dos participantes, obedecendo também, ao princípio recomendado nestes casos de exclusão mútua [Bardin, 2006]. 


\section{RESULTADOS}

As respostas obtidas a partir da questão Para si o que é a Universidade? foram submetidas a análise de conteúdo. A percepção sobre o que é a Universidade foi descrita evidenciando aspectos relacionados com a sua missão na actualidade [i a iv] e características de pendor algo negativo relativas à sua estrutura e funcionamento [ $\mathrm{v}$ e vi].

O conceito de Universidade surge centrado na descrição da sua missão. Os professores focaram essencialmente quatro aspectos: Universidade como contexto de produção e difusão de pensamento/conhecimento para a sociedade/mundo, como espaço de pensamento criativo e crítico sobre o mundo, como espaço multidisciplinar/interdisciplinar e como sistema centrado no ensino e na investigação. Como podemos observar nos exemplos que em seguida apresentamos a percepção de universidade está contaminada pelos vários modelos embora o discurso dos professores acentue mais a visão da universidade como produtora e difusora de conhecimento para a sociedade/mundo, o que nos permite inferir a existência de alguma prevalência da linguagem do modelo da sociedade do conhecimento.

\section{i) Universidade percebida como contexto de produção e difusão de pensamento/ conhecimento para a sociedade/mundo.}

A Universidade é vista como comprometida com a utilidade e transferência do conhecimento para o progresso da sociedade na linha de pensamento de Adam Smith e de Bentham, entroncada no conceito mais recente de uma sociedade mais ampla considerada como "sociedade do conhecimento".Esta ideia foi apropriada pelos professores deste estudo, no entanto não é claro se têm consciência, tal como refere Barnett [2004], de que na sociedade do conhecimento a sociedade acaba por gerar as suas próprias definições de conhecimento legítimo, o que pode colocar alguma dificuldade ao conceito de "liberdade académica" e até mesmo de "comunidade académica", numa visão mais clássica dos conceitos, como podemos observar nos exemplos que se seguem.

"A universidade hoje já não é o espaço limitado onde o conhecimento está inscrito. 0 conhecimento [informação] está distribuído e acessível e neste contexto a universidade está livre das amarras dos métodos expositivos"... "A universidade já não está circunscrita a espaços limitados. Com as tecnologias digitais também ela está distribuída pelo mundo". [S3]

"O lugar onde se produz e divulga, em primeira mão, o conhecimento" [S4]

“Um espaço cada vez mais ligado à vida e aberto ao mundo" [S5]

"Um espaço de produção de conhecimento, cruzamento de ideias e experiências educativas, de transmissão de conhecimentos e estimulação ao desenvolvimento sustentado do saber e da inovação científica e tecnológica" [S7].

"A Universidade desejável seria uma instituição na qual o conhecimento seria construído e partilhado, numa lógica de transferência, plasmado em edições científicas validadas por pares e passível de discussão na comunidade educativa" [S8]

"É um local de produção e transferência de conhecimento" [S9]

"Local de aprendizagem e construção de novos conhecimentos... partilha e troca de ideias, perspetivas e conhecimentos; Local que promove a abertura à compreensão do mundo... que deve promover atitudes de cidadania global" [S10] 


\section{ii] Espaço de pensamento criativo e crítico e sobre o mundo}

Podemos inferir alguma influência de uma perspectiva mais kantiana onde a capacidade de pensar e julgar pode [deve] ser exercida de forma livre e independente num contexto de liberdade académica. Observamos que apenasum dos professores refere este aspecto o que nos permite supor que a ideia de universidade como produtora de grandes ideias universais seja hoje, face ao que é exigido pelo modelo mais economicista e regulado que se tenta impor, uma visão reservada aos professores mais idealistas ou "românticos".Jarvis [2001] considera que a ideia da universidade como "a consciência crítica da sociedade" parece um ideal que já não pode ser realizado em universidades corporativas que funcionam com modelos empresariais e assumem agendas, valores e princípios operacionais da sociedade em geral, inviabilizam a existência de um certo ideal da universidade capaz de transformar o mundo pelo pensamento que produz.

"É um espaço onde se pode exercer o pensamento activo, onde se desenvolvem hábitos do espírito, que vão muito para além da utilização de informação... A universidade é um espaço ...onde se exerce o espírito crítico ...É um lugar para o exercício da "inteligência inventiva" em que alunos e professores têm de estar habitados pela chama da imaginação e da fruição". [S3]

\section{iii] Espaço multidisciplinar/ interdisciplinar}

O discurso em torno da necessidade de responder aos novos desafios e que exigem abordagens e soluções inovadoras a partir do cruzamento de diversas fontes disciplinares entrou na academia. Sabemos, todos os professores/investigadores, que tais condições são incontornáveis no financiamento da investigação e no próprio desenho dos curricula, pelo que não causa estranheza encontrá-la no discurso dos professores.

“...é uma estrutura organizacional em que a construção e a [re]construção de saberes se faz em comunidades que agregam pessoas da mesma área do saber, ou, cada vez mais, de áreas de saber diferentes" [S2].

"A universidade é um espaço de acontecimentos interdisciplinares". [S3]

\section{iv] Sistema centrado no ensino e na investigação}

Embora a maioria das universidades europeias inclua as vertentes de ensino e investigação, a introdução dos pressupostos de Bolonha associados à agenda da Estratégia de Lisboa acentuaram a componente de investigação como um aspecto central nas universidades, o que é percebido pelos professores deste estudo.

“A Universidade é...o local onde desenvolvo a minha actividade enquanto docente e investigador"[S1]

"Um sistema em que a investigação toma centralidade, mas que se retroalimenta entre o ensino, a inovação e o desenvolvimento sustentável” [S2]

"Um espaço de produção de conhecimento através da investigação"..."Um espaço social e cultural com extrema responsabilidade na aprendizagem de saberes de natureza científica e profissional” [S5]

Um espaço de formação, aprendizagem e investigação. [S6] 
Oconceito de Universidade incluitambém características relativas à sua estrutura e funcionamento e, neste caso, os professores evidenciam aspectos mais negativos. Encontramos referências à estrutura muito hierarquizada, complexa e burocrática da instituição e a percepção de uma crescente funcionarização dos docentes. A percepção da Universidade como espaço competitivo e desumanizado, marcado por uma hipervalorização da bibliometria é outro aspecto presente no discurso dos professores.

\section{v] Universidade percebida como espaço hierarquizado e burocrático}

A complexidade da organização da instituição,a sua hierarquização, a cultura organizacional e a crescente funcionarização dos professores são os aspectos referidos e sentidos como constrangimentos. Vimos anteriormente que nas universidades a mudança de organização [para uma cultura mais empresarial] implica passar de modelos horizontais para modelos verticais [Leite, 2003], o que acaba por causar perplexidade nos docentes e ter impacto ao nível da investigação. Estando associado a estes aspectos o conceito de eficiência, reforçado por mecanismos de avaliação interna e externa é compreensível a percepção que os professores apresentam.

"A cultura organizacional é, muitas vezes, uma barreira"... " [S3]

"Enquanto instituição obedece a uma estrutura altamente hierarquizada de organização complexa" [S5]

"A universidade real é uma instituição na qual o anteriormente enunciado se vê constrangido por uma crescente funcionarização dos professores" [S8]

\section{vi] Espaço competitivo e hipervalorização da bibliometria}

A competição, a desumanização e a pressão em termos de produção científica centrada em critérios bibliométricos são referidos pelos professores. Os mecanismos de avaliaçãoda qualidade introduzidos nos sistemas de ensino superior, onde se inclui também a avaliação dos professores, por norma muito centrados em critérios bibliométricos,não serão alheios a esta percepção. A perda de liberdade académica [no sentido kantiano, ou mais extremo humboldtiano] está a ser sacrificada em contextos em que o conhecimento deixa de ser visto como um fim em si mesmo para ser visto como um meio, um instrumento, numa cultura universitária marcada pelo conceito empresarial. É neste sentido que Becher e Trowler [2001] olham a "comunidade académica" na moderna universidade como um conjunto de tribos e territórios académicos enfraquecidos resultantes da perda dos conceitos-chave que uniram a universidade nos últimos duzentos anos e que são forçados, de algum modo, a competir entre si.

"As dinâmicas que ocorrem são, a maior parte das vezes, o efeito de valores de competição que habitam as universidades. A humanização, aspecto central da criação de futuro, está ausente. [S3]

"A universidade real é uma instituição na qual [existe] uma pressão... uma hipervalorização de critérios bibliométricos, pouco compativel com as condições criadas pela maioria das instituições" [S8] 


\section{CONCLUSÃO}

Bauman [2000] observou uma diferença crescente entre os tipos de desafios projetados para a universidade moderna e os desafios que enfrentamos no mundo incerto, complexo e em rápida mudança. Esta diferença marca a crise educacional de hoje que se deveprincipalmente à crise das instituições e das filosofias herdadas,com significado num determinado tipo de realidade. De algum modo esta perspectiva reflete-senuma certa perspectiva hibrida dos professores sobre a universidade, mesclada por alguma ambivalência resultante de valores académicos tradicionais mais cépticos em contraponto com a desejabilidade de mudança e identificação com objectivos gestionários considerados razoáveis, o que pode estar a contribuir para alguma dificuldade na construção da sua identidade enquanto professores e a dificultar a identificação com uma instituição em mudança de paradigma. Parecem ser, no entanto, a verticalização e burocratização da organização universitária, a excessiva competitividade e a pressão trazida pelos padrões da bibliometria os pontos mais sensíveis para estes professores. Tanto mais quanto esta deriva da universidade para modelos contabilísticos maquilhados pelo discurso da excelência acarreta consigo a crise identitária do docente universitário que assiste à desprofissionalização e correlativa funcionarização do seu estatuto.

\section{REFERENCIAS}

Bardin, L. [2006]. Análise de conteúdo. Lisboa: Edições 70.

Barnett, R. [2000]. Supercomplexity and the Curriculum. Studies in Higher Education, 25 [3], 255-265.

Barnett, R. [2004]. The Purposes of Higher Education and the Changing Face of Academia.London Review of Education, 2[1],61-73.

Bauman, Z. [2000]. Modernidade Líquida. Rio de Janeiro: Jorge Zahar Editor.

Becher, T. and Trowler, P. [2001]. Academic Tribes and Territories: intellectual enquiry and the cultures of disciplines [2nd edition]. Buckingham: Open University Press/SRHE.

Chaleta, E.; Pissarra, J. y Jesuino, J.C. [2018]. Quality and Excellence in the Portuguese Higher Education. In M. Rabossi, K.M. Joshi \& Saeed Paivandi [Eds.], In pursuit of world classuniversities - a global experience. Perspectives on Higher Education. Delhi: Studera Press.

Costa, J. V. [2001]. A Universidade no seu Labirinto. Lisboa: Editorial Caminho.

De Wit, K., and Verhoeven, J. [2001]. The higher education policy of the European Union: With or against the member states? In J. Huisman, P. Maassen\& G. Neave [Eds.], Highereducation and the Nation State. The international dimension of higher education [pp. 175-231]. Amsterdam: Pergamon.

Falcão, C. [2013]. Concepções sobre os afectos e as relações com pares em adolescentes com diagnóstico de ansiedade social. Tese de Doutoramento em Psicologia (não publicada). Évora: Universidade de Évora. 
Faria, L. L. [2003]. Universidade e Cultura. Lisboa: Universidade Católica Portuguesa

Foucault, M. [1969/2009]. A Arqueologia do Saber. Rio de Janeiro: Forense Universitária.

Fulton, 0. [2003]. Managerialism.In A. Amaral et al [Eds.], The Higher Education Managerial Revolution [pp.155-178]. Kluwer Academic Publications.

Gallagher, S. and Zahavi, D. [2008). The phenomenological mind: An introduction to philosophy of mind and cognitive science. Abbingdon: Routledge.

Gornitzka, A. [2010]. Bologna in context: A horizontal perspective on the dynamics of governance sites for a Europe of Knowledge. European Journal of Education, 45 [4], 535-548.

Habermas, J. [1990]. The Philosophical Discourse of Modernity. Cambridge: Polity.

Holanda, A. [2006]. Questões sobre pesquisa qualitativa e pesquisa fenomenológica. Análise Psicológica, 3 [XXIV], 363-372.

Huisman, J., Adelman, C., Hsieh, C.C., Shams, F., and Wilkins, S. [2012]. Europe's Bologna process and its impact on global higher education. In D.K. Deardorff, H. de Wit, J.D. Heyl, and T. Adams [eds.], The SAGEHandbook of International Higher Education, pp. 81-100. Thousand Oaks: Sage Publications.

Humboldt, W. [1810/1997]. Sobre a organização interna e externa das instituições científicas superiores em Berlim. Rio de Janeiro: EdUERJ.

Jarvis, P. [2001]. Universities and Corporate Universities: The Higher Learning Industry in Global Society. UK: Routledge.

Jesuíno, J. C. [2016] Introdução. In M. Sobrinho, R. Ennafaa \& E. Chaleta [Eds]. La Educación Superior, el Estudiantado y la Cultura Universitaria [pp. 15-36] . Valência: Ed. Neopatria

Kant, I. [1995]. A Paz Perpétua e outros Opúsculos. São Paulo: Edições 70.

Keeling, R. [2006]. The Bologna process and the Lisbon research agenda: the European Commission's expanding role in higher education discourse. European Journal of Education, 41[2], 203-223.

Kehm, B., Huisman, J., \&Stensaker, B. [Eds.]. [2009]. The European Higher Education Area: Perspectives on a moving target. Rotterdam: Sense.

Leite, D. [2003]. Institutional Evaluation, Management Practices and Capitalist Redesign of the University: A case Study.In A. Amaral et al [Eds]. The Higher Education Managerial Revolution [pp.253-273]. Kluwer Academic Publications.

Lyotard, J. F. [1984] The Postmodern Condition: a report on knowledge. Manchester: Manchester University Press.

Moustakas, C. [1994]. Phenomenological research methods. Thousand Oaks: Sage. 
Neave, G. [2002). Anything goes: Or, how the accommodation of Europe's universities to European integration integrates an inspiring number of contradictions. Tertiary Education and Management, 8 [3], 181-197.

Neave, G., \&Maassen, P. [2007]. The Bologna process: An intergovernmental policy perspective. In P. Maassen\& J. P. Olsen [Eds.], University dynamics and Europeanintegration [pp. 135-153]. Dordrecht: Springer.

Newman, J. H. [1854]. The idea of a University. Project Guttenberg.

Rauhvargers, A. [2011]. Achieving Bologna goals: Where does Europe stand ahead of 2010. Journal of Studies in International Education, 15[4], 4-24.

Readings, B. [2003]. A UniversidadeemRuinas. Coimbra: Angelus Novus.

Rey, F.G. [1999]. La investigación cualitativa en Psicologia - Rumbos y desafios. S. Paulo: EDUC.

Roldão, M. C. [2005]. Profissionalidade docente em Análise: especificidades dos ensinos superior e não superior. Nuances: estudos sobre educação, 12 [13], 105-126.

Paquay, L., Altet, M., Charlier and Perrenoud, P. [1998). Former des enseignants professionnels. Paris: De Boeck \& Larcier.

Smith, J.A. [1996). Beyond the divide between cognition and discourse: Using interpretative phenomenological analysis in health psychology. Psychology \&Health, 11, 261 - 271.

Smith, J.A., Flowers, P. \& Larkin, M. [2009]. Interpretative Phenomenological Analysis: theory, method and research. London: Sage.

Van der Wende, M., \& Huisman, J. [2004). Europe. In J. Huisman \& M. Van der Wende [Eds.], On cooperation and competition. National and European policies for theinternationalization of higher education [pp. 17-49]. Bonn: Lemmens

Westerheijden, D. F., Beerkens, E., Cremonini, L., Huisman, J., Kehm, B., Kovač, A., et al. [2010]. The first decade of working on the European Higher Education Area. Bologna process independent assessment volume 1: Main report. Enschede: CHEPS.

Witte, J. [2006]. Change of degrees and degrees of change. Comparing adaptations of European higher education systems in the context of the Bologna process. Enschede: CHEPS.

Witte, J., Huisman, J., and Purser, L. [2009]. European higher education reforms in the context of the Bologna process: How did we get here, where are we and where are we going?

Zgaga, P. [2006]. Looking out: The Bologna process in a global setting. Oslo: Norwegian Ministry of Education and Research. 